\title{
The long flight towards clean aviation
}

Written by: Vincent Benezech, International Transport Forum

Last update: 25 June 2018

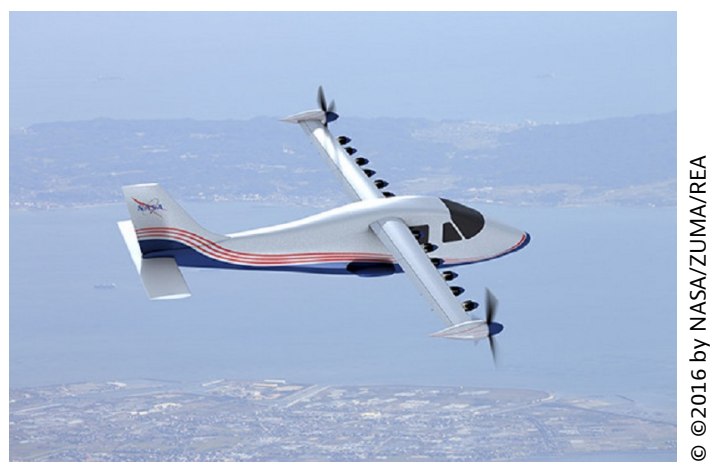

The Paris climate summit in November 2015 was a great diplomatic success but aviation, like shipping, was not included in the final agreement. International air transport currently represents about $1.5 \%$ of all man-made emissions, though with a projected doubling of demand for air travel over the next 10-20 years, up from approximately 3.5 billion in 2015, action had to be taken.

In 2016, the 192 member states of the International Civil Aviation Organisation (ICAO) forged a ground-breaking agreement. Aircraft operators will collectively offset, or compensate for, $\mathrm{CO} 2$ emissions that go above a threshold based on the average of 2019/20 emissions. Following a trial phase between 2021 and 2023 and a voluntary phase between 2024 and 2026, the Carbon Offsetting and Reduction Scheme for International Aviation (CORSIA) will become mandatory, with a few exceptions, for instance for least developed countries.

As a global, sector-wide emissions-reduction mechanism, CORSIA is one of the first of its kind. It will ensure that emissions from international aviation stop growing after 2020 even if demand for air travel keeps rising.

But the ambitions of the aviation industry, represented by the Air Transport Action Group, do not stop there.

\section{Emissions reductions and improved efficiency}


In addition to carbon-neutral growth, airlines, airports and aircraft manufacturers are also committed to bringing aviation emissions down to half of its 2005 level by 2050 regardless of any increase in demand.

Better aircraft and improved operations render flying more fuel efficient. In the past decade or so, fuel use per passenger and per kilometre has fallen by more than $2 \%$ annually-quite an achievement compared with the $1 \%$ reduction for an average car in Europe. But at the same time, it's an insufficient achievement since the number of air travellers grew at a yearly rate of 5-6\% and efficiency gains should be aligned with the increase in passenger volumes for carbon-neutral growth.

Efficiency improvements are set to continue with ICAO agreeing on global efficiency standards for new airplanes from 2020 and for currently produced aircrafts as of 2023. At the same time, $\mathrm{CO} 2$ offsets will decrease emissions in sectors and regions, notably in developing countries where it is easier and less costly to put in place, and will buy some time for the sector to develop new solutions, such as advanced-generation biofuels.

\section{$B$ iofuels and electric planes}

While only a fraction of aviation fuel comes from such low-carbon bio-sources today, there is intense research and development on advanced generation biofuels, and several airlines are running trials with them. But there are many constraints. Biofuels produced from non-food crops have only limited global availability and are still too expensive to produce at scale. So far, they are not costcompetitive compared to conventional kerosene, which remains consistently cheap and in full supply. Additionally, growing competition between economic sectors for sustainable forms of energy is likely, and aviation may not hold the best hand. Precious biofuels may be better allocated to, for instance, carbonnegative electricity power generation, which captures and stores $\mathrm{CO} 2$ during the electricity production phase.

The airline industry has other technological innovations in the pipeline, for instance, electric planes. But, as with biofuels, many uncertainties remain as to the exact potential of this technology. A recent announcement by a major European low-cost carrier that they would be flying battery-powered planes on short-haul flights in a decade or so was met with both hope and scepticism.

\section{Enhancing aviation's sustainability}

Aviation's share of global CO2 emissions is still relatively small, but even so, is it worth considering creating incentives to fly less to mitigate emissions? After all, demand management is one of the pillars of climate mitigation strategies for surface transport.

It actually wouldn't really be feasible or equitable to do so. Already, less than $5 \%$ of the world population flies in a given year. Any global increase in ticket prices 
would mostly hit people in emerging markets who have only just begun to connect with the world through international aviation. Within developed economies, a general increase in ticket prices would hurt the poorest travellers, and tourism as a whole would be affected too.

A better way to frame the question is to ask how the societal benefits of aviation can be maximised. How can policymakers help air travel contribute more to economic and social development, and reduce inequality, by bolstering regional development for instance? Some voices in the sustainable tourism sector argue that one option would be to encourage longer trips. By spending more time at a destination, visitors would not only inject more money into local communities but would be better able to partake in a wider range of activities. This would also help people integrate more, and bridge divides.

Remembering that flying is a means to an end that should help aviation move in a more sustainable and inclusive direction.

\section{References}

ATAG (2015) Aviation Climate Solutions, Air Transport Action Group. https:// aviationbenefits.org/media/125796/Aviation-Climate-Solutions_WEB.pdf

ICAO (2016) Assembly Resolution A39-3, containing Resolution 22/2 "Consolidated statement of continuing ICAO policies and practices related to environmental protection - Global Market-based Measure (MBM) scheme", adopted at the 39th session of the International Civil Aviation Organisation Plenary Assembly, October 2016, Montreal. https://www.icao.int/Meetings/a39/ Documents/WP/wp_530_en.pdf

IRENA (2017) Biofuels for Aviation, Technology Brief, International Renewable Energy Agency. http://www.irena.org/documentdownloads/publications/ irena_biofuels_for_aviation_2017.pdf

ITF Transport Outlook 2017 http://dx.doi.org/10.1787/9789282108000-en

CO2 emissions from international aviation http://dx.doi.org/ 10.1787/9789282108000-graph51-en 